\title{
Fortification of Fibre in Yogurt using High Fibre Banana Stem and Jack Fruit Powder
}

\author{
Kaliyamoorthy Jayabalan*, Arangasamy Magesh, Rajan Rajeshkannan, Palani Rathakrishnan \\ Department of Chemical Engineering, Annamalai University, Annamalai Nagar, Chidambaram, Tamil Nadu, INDIA.
}

\begin{abstract}
Objectives: The present work is focused on the sensory quality of yogurt produced with high fibre powder. Methods: Response surface methodology (RSM) was used to optimize the ingredients like: Milk (1000 $\mathrm{ml})$, sugar $(100 \mathrm{~g})$, Jack fruit powder $(20 \mathrm{~g})$ and Banana Stem Powder $(25 \mathrm{~g})$. Results: The results showed that the model fit was significant $(p<0.05)$ and there was satisfactory correlation between actual and fitted values. The statistical model was used to optimise the factors level for highest acceptability, to produce yogurt with high fibre. Data obtained from RSM on yogurt produced with high fibre banana stem powder and Jack fruit powder were subjected to the analysis of variance (ANOVA) and analyzed using a second order polynomial equation. Sensory analysis for colour and taste in the yogurt produced with banana stem powder and Jack fruit powder at the optimized ingredients composition were performed. Conclusion: The optimum condition for the best sensory score is Milk- $826 \mathrm{ml}$, Sugar- $99.8 \mathrm{~g}$,
\end{abstract}

Jack fruit powder $20.3 \mathrm{~g}$ and Banana Stem Powder-22.5g. Yogurt produced with high fibre powder under the optimum conditions for sensory score was again subjected to evaluation of sensory values and the results were compared with the RSM predictions.

Key words: Milk, Sugar, Jack fruit powder, Banana Stem Powder, Response surface methodology, Central composite design.

\section{Correspondence}

Dr. Kaliyamoorthy Jayabalan

Department of Chemical Engineering, Annamalai University, Annamalai Nagar-608002, Chidambaram, Tamil Nadu, INDIA

Phone no: +91 8838908032

Email: drkjs1978@gmail.com

DOI: 10.5530/ijpi.2020.2.23

\section{INTRODUCTION}

Banana is a rhizomatous plant and it grows nearly in 129 countries around the world. ${ }^{1}$ It is the fourth most important global food. ${ }^{2}$ The banana tree had numerous parts which serve as diverse needs, including fruits as food sources, leaves as food wrapping and stems for fibre and paper pulp. As historical evidence from the $13^{\text {th }}$ century banana stems had been used as a source of fibre. ${ }^{3}$ India takes second place in the production of banana, the major banana producing states are Maharashtra, Kerala, Tamil Nadu, Gujarat, Bihar, West Bengal, Assam, Andhra Pradesh and Karnataka. Banana is mainly cultivated for fruit, but in plenty amount is used to make fibre and nowadays, its major function of its tree is used as ornamental plant. ${ }^{4}$ Constitution of plant biomass is a major part by Pseudo-stem (BPS), which are usually left in the plantation or incinerated and wasted. The nutritive properties of BPS, it be an ironic source of fibre, total carbohydrate and cellulose. ${ }^{5}$

Banana plant (scientific name: Musa acuminata) is not only the source of tempting fruits, it also has the nature of providing fabric fibre, which is used as banana fibre. It is commonly found in hot tropical climate and grows easily as it groups out as young shoot. An abundance amount of fibre is present in all varieties of banana. Pseudo stem, i.e. trunk of the banana plant is thrown as agricultural waste to a great extent after the production of fruit. But nowadays it is used in effective manner, nearly 1.5 million tons of dry banana fibre can be produced per year from the outer sheath of pseudo stem. For preparation of various products, Biomass a rich source of natural fibre is used.

Jackfruit is a seasonal fruit, which is a rich source of more protein, calcium, thiamine, riboflavin and carotene. ${ }^{6}$ Mostly it can be consumed as a fruit and also used as a vegetable in unripe condition by the people in all over the world. The nutritive source of the jackfruit is a source of Vitamins, minerals and calories. The seeds are rich in minerals and
Vitamins. Mainly, the jackfruit is cultivated for their fruit and used in all stages. Its pulp is sweet and taste in nature, it is used for preparation of syrup and for the preservation of syrup. Processing of their fruits and seeds were taken place for making other food products. ${ }^{7}$

Jackfruit is a fibre rich fruit. The importance of fibre is helps to protect the colon, mucous membrane by decreasing exposure time and as well as binding to cancer-causing chemicals in the colon. The nutritional source of fresh fruits is, small amounts of Vitamin-A and flavonoid pigments such as carotene- $B$, xanthine, lutein and Cryptoxanthin- $B$. It also plays a role for its antioxidant and vision functions. ${ }^{8}$ Due to technology, the food processing wastes are used as nutrition source as a favour which includes promising source of dietary fibre, antioxidants, essential fatty acids, antimicrobials and minerals. ${ }^{9}$ The functional source of dietary fibre is resistant to hydrolysis by human digestive enzymes and necessary for promoting good health. ${ }^{10}$ The therapeutic properties of this source include, enhance digestive process, stimulates bowel movements, lowers cholesterol and exerts a positive influence on blood sugar levels. ${ }^{11}$ It creates awareness on consumption of food with high fibre content to maintain its function in the prevention of diabetes mellitus, obesity, coronary heart diseases, colon cancer and maintaining weight. ${ }^{12}$

Yoghurt is a fermented milk product that contains the characteristic bacterial cultures Lactobacillus bulgaricus and Streptococcus thermophilus. The number of solids non-fat (SNF) present in all types of yoghurt is, at least $8.25 \%$. The amount of milk present in yogurts are, Full fat yoghurt must contain not less than $3.25 \%$ milk fat, low fat yogurt not more than $2 \%$ milk fat and non-fat yogurt less than $0.5 \%$ milk. Milk is the main ingredient in yoghurt preparation. The type of milk used depends on the type of yogurt - whole milk for full fat yogurt, low fat milk for low fat yogurt and skim milk for non-fat yoghurt. Other dairy ingredients are 
added to adjust the composition of milk, such as cream to adjust the fat content and non-fat dry milk to adjust the solids content. Above $8.25 \%$ of solids content of yogurt is adjusted as minimum level for providing a better body and texture to the finished yoghurt. It owns a fresh lactic acid smell and its characteristic taste is pleasant, full and slightly too intense sour. Because yogurt contains an abundant and viable micro flora of starter origin at the time of consumption and low $\mathrm{pH}$, it is considered generally safe if possible post-pasteurization decontamination is prevented. ${ }^{13}$

Antioxidant activity of some yogurt starter cultures, ${ }^{14}$ the shelf life of yogurt products is usually three weeks or less at refrigerated storage in Korea. In addition, immune-compromised patients can be suffering from these health-promoting microorganisms present in yogurt. In recent years, because of increasing competition in the market as well as considerable attention has been paid by the consumer. They are interested and demanding for healthy, natural, functional and herbal food products.

\section{MATERIALS AND METHODS}

\section{Ingredients used for yogurt}

The following are the ingredients to be used in the preparation of high fibre yogurt. Like as Milk, sugar, Jack fruit powder and Banana Stem Powder were obtained from market

\section{Sample Preparation}

\section{Method of banana stem powder preparation}

The raw banana stem collected locally from farmer field. The banana stem were sliced into small pieces and crushed into the mixture. The juice was extracted by using cotton cloth manually. After filtering juice, the fibre was separated. The matured fibre was dried at $70^{\circ} \mathrm{C}$ in tray dryer until mature removal. The fully dried fibre was ground in powder form.

\section{Method of jack fruit powder preparation}

The raw Jack fruit collected from the local market. The ripen fruits are sliced into small pieces and crushed into the mixture. The juice was extracted by using cotton cloth manually. After filtering juice substrate was separated. The matured substrate was dried at $70^{\circ} \mathrm{C}$ in tray dryer until mature removal. The fully dried substrate was packed in air tight conditioner.

\section{Method of yogurt preparation using jack fruit and banana stem powder}

Cow milk had taken with incorporation of Banana Stem Powder and Jack fruit powders were used for standardization. The incorporated milk is heated at $65^{\circ} \mathrm{C}$ for $10 \mathrm{~min}$ and the homogenization of milk was done. The homogenized milk and other mixtures were heated at $90^{\circ} \mathrm{C}$ for $30 \mathrm{~min}$. The mixture was cooled at $42^{\circ} \mathrm{C}$ to bring the mixture to the ideal growth temperature for addition of starter culture. Two mixed culture of S. thermophilus and L. delbruecki ssp. bulgaricus was added to the mixtures. The incubation was done at $42^{\circ} \mathrm{C}$ for $3-4 \mathrm{hr}$ and the product was stored at $5-7^{\circ} \mathrm{C}$. The prepared yogurt is packed in an air tight conditioner.

\section{Sensory analysis}

Sensory evaluation of yogurt fortified with high fibre powder were carried out based on the organoleptic attributes like colour and taste by 50 members ( 35 males and 15 females) panel, consisting of faculty and graduate students of the Department of Technology, Annamalai University. The samples are evaluated by the following nine-point hedonic scale 9 - like extremely; 8 - like very much; 7 - like moderately; 6 - like slightly; 5 - Neither like nor dislike; 4 - Dislike slightly; 3 - Dislike moderately; 2 - Dislike very much; 1 - Dislike extremely.

\section{RESULTS}

Central Composite Design (CCD) is used to optimize the ingredients for sensory evaluation of fortified yogurt produced using high fibre powder. The ingredients are optimized to enhance the quality of respective processed food products.

\section{Optimization of yogurt produced with using high fibre} banana stem powder and jack fruit powder ingredients using RSM

The independent ingredients selected for this study are Milk, Sugar, Jack fruit powder and Banana Stem Powder. A CCD contains totally 31 experimental trials involved the replications of seven central points is used to study the linear, square and interactive effects of the four ingredients on yogurt production with Jack fruit and Banana Stem Powder based on sensory analysis properties namely colour and taste. The design and the results based on sensory analysis for colour and taste are given in Table 1.

The student's $t$-test for factor coefficients and the corresponding $p$-values for sensory evaluation of yogurt produced with high fibre Jack fruit and banana stem powder are given in Table 2 .

The sign of the estimated coefficient gives the effect of the ingredients on response. In this way, when a factor has a positive value, the response is high at the higher level $(+)$ and when the factor has a negative value, the response is low at higher level $(+)$. The $\mathrm{p}$ values are used as a tool to check the significance of each coefficient, which may in turn indicate the pattern of the interactions between the ingredients. The smaller the value of $p$, the corresponding coefficient is more significant. $P$ values less than 0.05 indicates the significance of the model term.

Optimization of yogurt produced with high fibre powder production for sensory analysis, the results obtained were given in Table 1. A polynomial model was proposed for sensory analysis of foods in the production of yogurt produced with high fibre powder. The two outputs, namely colour and taste of the product were given as polynomials in equations (1) and (2) respectively,

ANOVA for the response surface methodology was given in Table 3 and Table 4 for colour and taste respectively. The F values are 68.07 for colour and 115.73 for taste implies the model is significant. Generally, value of "prob > F "was less than 0.05 indicate that, the model term is significant. Values greater than 0.1 indicate that the model terms are not significant. $\mathrm{Y}=8.8819-0.3239 \mathrm{~A}+0.1928 \mathrm{~B}+0.2239 \mathrm{C}-0.6511 \mathrm{D}-0.6437 \mathrm{~A}^{\star} \mathrm{A}-0.3373 \mathrm{~B}^{\star} \mathrm{B}$ $\begin{array}{llllll}-0.5125 & \mathrm{C}^{\star} \mathrm{C} & -0.6562 & \mathrm{D}^{\star} \mathrm{D} & +0.6671 & \mathrm{~A}^{\star} \mathrm{B}\end{array}$ $-0.1297 \quad \mathrm{~A}^{\star} \mathrm{C}+0.1391 \quad \mathrm{~A}^{\star} \mathrm{D}+0.2142 \quad \mathrm{~B}^{\star} \mathrm{C}$

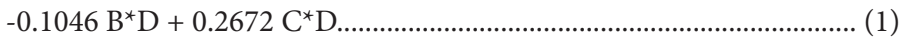

$\mathrm{Y}=9.00000-0.12117 \mathrm{~A}+0.15592 \mathrm{~B}+0.09408 \mathrm{C}$ $\begin{array}{llllll}-0.66217 & D & -0.70981 & A^{*} A & -0.36606 & B * B\end{array}$ $-0.53481 C^{\star} C-0.74106 D^{\star} D+0.70050 A^{\star} B+0.11825 A^{\star} C+0.35263 A^{\star} D$ $+0.22762 B^{\star} C+0.10575 B^{\star} D+0.18800 C^{\star} D$.

\section{DISCUSSION}

In the present work, all the linear, square and interactive effect of $A B$, $\mathrm{AC}, \mathrm{AD}, \mathrm{BC} \& \mathrm{C} \mathrm{D}$ were significant for colour, all the linear, square and interactive effects were significant for taste. The coefficients of determination $\left(R^{2}\right)$ for sensory values were found to be 0.9835 for colour, 0.9902 for taste. The predicted $R^{2}$ value 0.9253 for colour, 0.9437 for taste is in reasonable agreement with the adjusted $R^{2}$ value of 0.9690 for colour, 0.9817 for taste.

The interactive effects of variables on sensory analysis of yogurt produced with high fibre powder production in the form of contour plots were 
Table 1: The responses for using yogurt with high fibre powder production based on Central composite design.

\begin{tabular}{|c|c|c|c|c|c|}
\hline \multirow{2}{*}{ Run no } & \multicolumn{2}{|c|}{ COLOR } & \multicolumn{2}{|c|}{ TASTE } & \multirow[b]{2}{*}{ Pred } \\
\hline & Exp & Pred & & Exp & \\
\hline 1 & 6.283 & 6.130 & 7.761 & 7.251 & 6.283 \\
\hline 2 & 9.000 & 9.000 & 9.000 & 8.882 & 9.000 \\
\hline 3 & 5.500 & 5.707 & 6.369 & 6.522 & 5.500 \\
\hline 4 & 9.000 & 9.000 & 9.000 & 8.882 & 9.000 \\
\hline 5 & 9.000 & 9.000 & 9.000 & 8.882 & 9.000 \\
\hline 6 & 6.400 & 6.289 & 6.394 & 6.343 & 6.400 \\
\hline 7 & 6.450 & 6.673 & 6.435 & 6.384 & 6.450 \\
\hline 8 & 9.000 & 9.000 & 9.000 & 8.882 & 9.000 \\
\hline 9 & 7.450 & 7.335 & 7.538 & 7.844 & 7.450 \\
\hline 10 & 6.450 & 6.257 & 6.285 & 6.438 & 6.450 \\
\hline 11 & 7.20 & 7.36 & 7.61 & 7.559 & 7.200 \\
\hline 12 & 7.050 & 7.224 & 6.994 & 7.147 & 7.050 \\
\hline 13 & 7.100 & 7.049 & 7.127 & 7.28 & 7.100 \\
\hline 14 & 5.950 & 5.918 & 5.71 & 5.659 & 5.950 \\
\hline 15 & 7.200 & 7.118 & 7.227 & 7.176 & 7.200 \\
\hline 16 & 9.000 & 9.000 & 8.586 & 8.882 & 9.000 \\
\hline 17 & 7.400 & 7.149 & 7.879 & 7.777 & 7.400 \\
\hline 18 & 6.200 & 6.403 & 6.802 & 6.955 & 6.200 \\
\hline 19 & 7.850 & 7.848 & 7.969 & 7.918 & 7.850 \\
\hline 20 & 7.550 & 7.839 & 7.977 & 7.926 & 7.550 \\
\hline 21 & 9.000 & 9.000 & 8.587 & 8.882 & 9.000 \\
\hline 22 & 6.075 & 5.883 & 5.671 & 5.569 & 6.075 \\
\hline 23 & 8.950 & 8.874 & 8.446 & 8.344 & 8.950 \\
\hline 24 & 7.950 & 7.995 & 7.935 & 8.088 & 7.950 \\
\hline 25 & 5.100 & 5.083 & 5.096 & 4.994 & 5.100 \\
\hline 26 & 8.000 & 7.808 & 7.329 & 7.227 & 8.000 \\
\hline 27 & 9.000 & 9.000 & 9.000 & 8.882 & 9.000 \\
\hline 28 & 4.700 & 4.711 & 4.802 & 4.955 & 4.700 \\
\hline 29 & 5.000 & 4.924 & 4.954 & 4.852 & 5.000 \\
\hline 30 & 5.250 & 5.428 & 5.135 & 5.288 & 5.250 \\
\hline 31 & 6.500 & 6.552 & 6.127 & 6.076 & 6.500 \\
\hline
\end{tabular}

Table 2: Regression coefficient and corresponding $t$ and $p$ value for sensory analysis (colour and taste) of using yogurt with high fibre powder.

\begin{tabular}{|c|c|c|c|c|c|c|}
\hline \multirow[b]{2}{*}{ Source } & \multicolumn{3}{|c|}{ Colour } & \multicolumn{3}{|c|}{ Taste } \\
\hline & $\begin{array}{l}\text { Regression } \\
\text { Coefficient }\end{array}$ & t-statistic & $P$-value & $\begin{array}{l}\text { Regression } \\
\text { Coefficient }\end{array}$ & $t$-statistic & $P$-value \\
\hline Intercept & 8.8819 & 100.898 & 0.000 & 9.00000 & 127.884 & 0.000 \\
\hline A & -0.3239 & -6.813 & 0.000 & -0.12117 & -3.188 & 0.006 \\
\hline B & 0.1928 & 4.055 & 0.001 & 0.15592 & 4.102 & 0.001 \\
\hline C & 0.2239 & 4.709 & 0.000 & 0.09408 & 2.475 & 0.025 \\
\hline $\mathrm{D}$ & -0.6511 & -13.696 & 0.000 & -0.66217 & -17.422 & 0.000 \\
\hline$A^{*} A$ & -0.6437 & -14.780 & 0.000 & -0.70981 & -20.385 & 0.000 \\
\hline$B^{\star} B$ & -0.3373 & -7.745 & 0.000 & -0.36606 & -10.513 & 0.000 \\
\hline $\mathrm{C}^{\star} \mathrm{C}$ & -0.5125 & -11.766 & 0.000 & -0.53481 & -15.359 & 0.000 \\
\hline$D^{*} \mathrm{D}$ & -0.6562 & -15.067 & 0.000 & -0.74106 & -21.283 & 0.000 \\
\hline$A^{\star} B$ & 0.6671 & 11.457 & 0.000 & 0.70050 & 15.048 & 0.000 \\
\hline $\mathrm{A}^{\star} \mathrm{C}$ & -0.1297 & -2.227 & 0.041 & 0.11825 & 2.540 & 0.022 \\
\hline$A^{*} D$ & 0.1391 & 2.388 & 0.030 & 0.35263 & 7.575 & 0.000 \\
\hline $\mathrm{B}^{\star} \mathrm{C}$ & 0.2142 & 3.679 & 0.002 & 0.22762 & 4.890 & 0.000 \\
\hline$B^{*} \mathrm{D}$ & -0.1046 & -1.796 & 0.091 & 0.10575 & 2.272 & 0.037 \\
\hline$C^{\star} \mathrm{D}$ & 0.2672 & 4.589 & 0.000 & 0.18800 & 4.039 & 0.001 \\
\hline
\end{tabular}

Table 3: Analysis of variance (ANOVA) for sensory analysis (Colour) of using yogurt with high fibre powder production.

\begin{tabular}{cccccc}
\hline \multirow{2}{*}{ Source } & \multicolumn{5}{c}{ Colour } \\
\cline { 2 - 6 } & SOS & DF & MS & F & P \\
\hline Regression & 51.6946 & 14 & 3.6925 & 68.07 & 0.000 \\
Linear & 14.7875 & 4 & 3.6925 & 68.15 & 0.000 \\
Square & 27.1579 & 4 & 6.7895 & 125.17 & 0.000 \\
Interaction & 9.7493 & 6 & 1.6249 & 29.96 & 0.000 \\
$\begin{array}{c}\text { Residual } \\
\text { Error }\end{array}$ & 0.8679 & 16 & 0.0524 & - & - \\
Lack-of-Fit & 0.6236 & 10 & 0.0624 & $1.53-$ & - \\
$\begin{array}{c}\text { Pure Error } \\
\text { Total }\end{array}$ & 0.2443 & 6 & 0.0407 & - & - \\
\hline $\begin{array}{l}\text { S }=0.232902, \\
\text { color }\end{array}$ & 52.5625 & 30 & - & - & - \\
\hline
\end{tabular}

shown in Figures 1-4. The experimental conditions for different sensorial score obtained and their response for the sensorial colour and taste were given in Table 1.

Figure 1, shows the significant interaction between yogurts produced, Jack fruit powder and banana stem powder for colour. The sensory value of colour increased with increase in yogurt produced with high fibre to about $19.9 \mathrm{~g}$ and $22.5 \mathrm{~g}$ respectively and thereafter sensory score decreases with further increase in yogurt produced with Jack fruit powder and banana stem powder. Figure 2, shows the significant interaction between yogurt produced, Sugar and Jack fruit powder for colour. The sensory value of colour increased with increase in yogurt produced with high fibre, Sugar and Jack fruit powder to about $99.6 \mathrm{gl}$ and $19.9 \mathrm{~g}$ respectively 


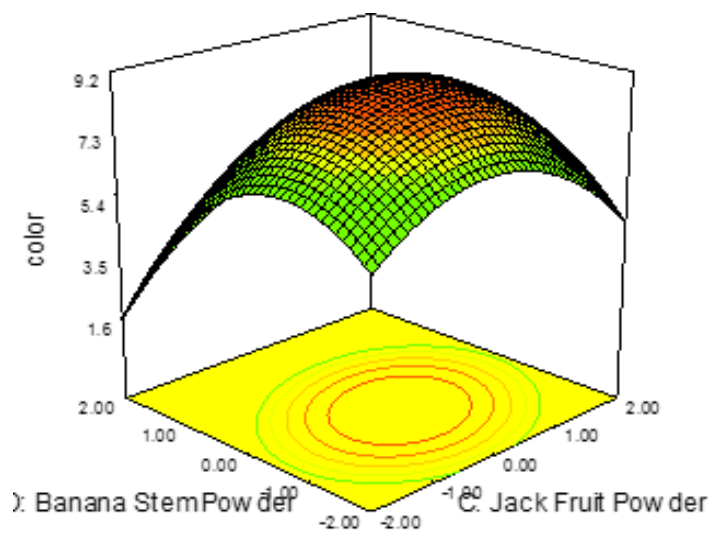

Figure 1: 3D plot showing the interactive effects of Jack fruit powder and Banana Stem Powder on sensory Analysis of yogurt with high fibre for colour.

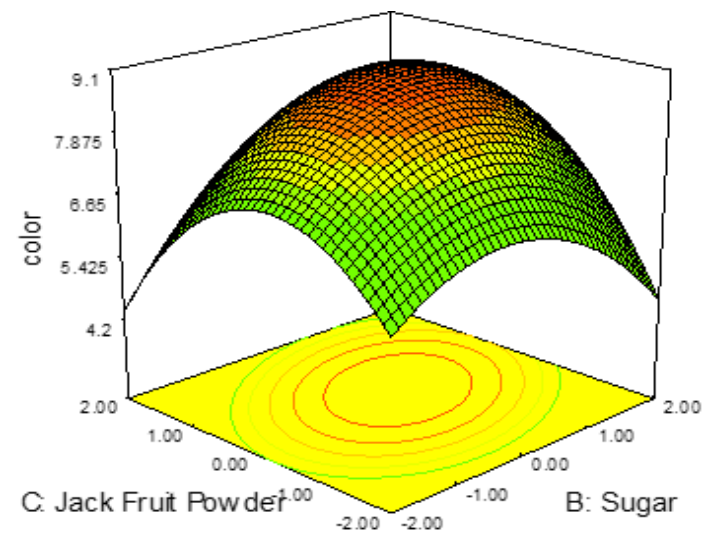

Figure 2: 3D plot showing the interactive effects of sugar and Jack fruit powder on sensory Analysis of yogurt with high fibre powder for colour.

\section{Table 4: Analysis of variance (ANOVA) for sensory analysis (Taste) of} using yogurt with high powder production.

\begin{tabular}{cccccc}
\hline \multirow{2}{*}{ Source } & \multicolumn{5}{c}{ Taste } \\
\cline { 2 - 6 } & SOS & DF & MS & F & P \\
\hline Regression & 56.1735 & 14 & 4.0124 & 115.73 & 0.000 \\
Linear & 11.6714 & 4 & 2.9178 & 84.16 & 0.000 \\
Square & 32.8642 & 4 & 8.2161 & 236.98 & 0.000 \\
Interaction & 11.6379 & 6 & 1.9396 & 55.95 & 0.000 \\
Residual & 0.5547 & 16 & 0.0347 & - & - \\
Error & & & & & - \\
Lack-of-Fit & 0.5547 & 10 & 0.0555 & - & - \\
Pure Error & 0.0000 & 6 & 0.0000 & - & - \\
Total & & 30 & - & - & - \\
\hline
\end{tabular}

$\mathrm{S}=0.186199, \mathrm{R}-\mathrm{Sq}=99.02 \%, \mathrm{R}-\mathrm{Sq}(\mathrm{pred})=94.37 \%, \mathrm{R}-\mathrm{Sq}(\mathrm{adj})=98.17 \%$ for taste

and thereafter sensory score decreases with further increase in yogurt produced with sugar and Jack fruit powder.

Figure 3, shows the significant interaction between yogurt produced, milk and sugar for taste. The sensory value of taste increased with increase in yogurt produced with milk and sugar to about $826 \mathrm{ml}$ and $100.2 \mathrm{~g}$ respectively and thereafter sensory score decreases with further

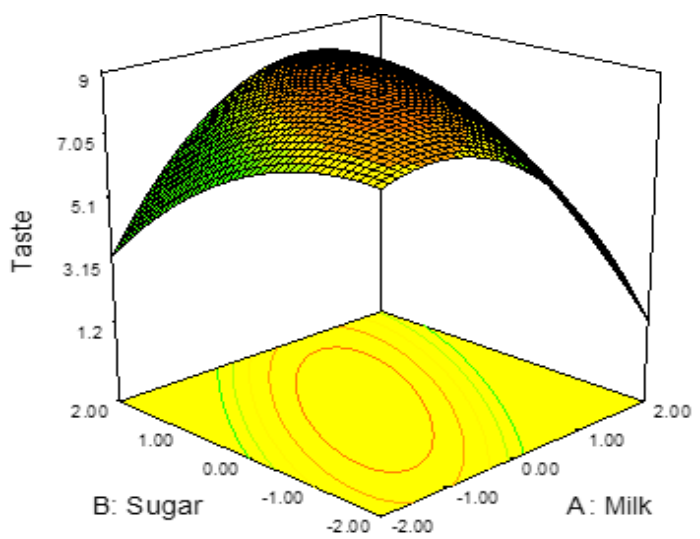

Figure 3: 3D plot showing the interactive effects of milk and sugar on sensory analysis of yogurt with high fibre for taste

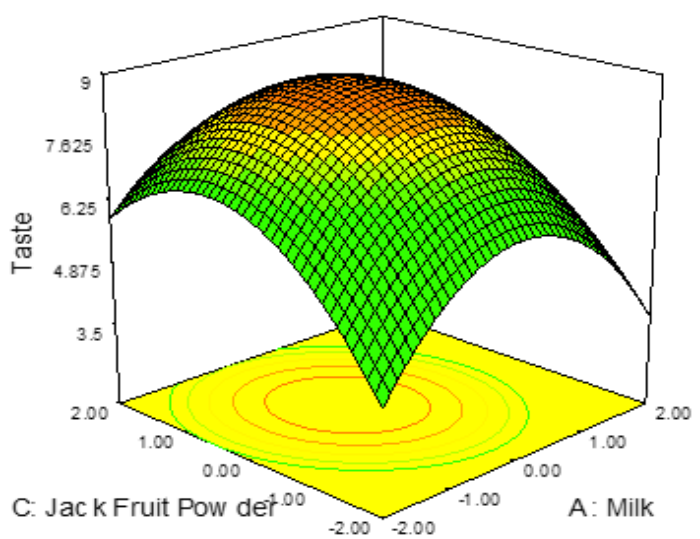

Figure 4: 3D plot showing the interactive effects of milk and Jack fruit powder on sensory analysis of yogurt with high fibre for taste.

increase in yogurt produced with milk and sugar. Figure 4, shows the significant interaction between yogurt produced, milk and Jack fruit powder for taste. The sensory value of taste increased with increase in yogurt produced with high fibre powder, milk and Jack fruit powder to about $826 \mathrm{ml}$ and $19.5 \mathrm{~g}$ respectively and thereafter sensory score decreases with further increase in yogurt produced with milk and Jack fruit powder.

\section{CONCLUSION}

The fortification of fibre in Yogurt with banana stem powder and Jack fruit powder produced and is clearly depicted in the study. The optimum compositions of ingredients for the production of yogurt produced with high fibre powder are studied using Response Surface Methodology (RSM). The optimum conditions for the best sensory score of the two outputs were obtained using Response optimizer in Minitab 16. They are: Milk- $826 \mathrm{ml}$, Sugar- 99.8g, Jack fruit powder- 20.3g and Banana Stem Powder-22.5g. The overall scores were 9.00 for colour and taste.

\section{ACKNOWLEDGEMENT}

The Author thanks the authorities of Annamalai University for permitting them to carry out this work at Food Processing Technology Laboratory, Department of Chemical Engineering.

\section{CONFLICT OF INTEREST}

The authors declare that there is no conflict of interest. 


\section{ABBREVIATIONS}

ANOVA: Analysis of variance; RSM: Response surface methodology.

\section{REFERENCES}

1. Lu P, Woo KC, Liu T. Estimation of Whole plant Transpiration of Bananas using Sap Flow Measurements. J Exp Bot. 2002;53(375):1771-9.

2. Wang $C$, King R. Chemical and sensory evaluation of iron fortified milk. J Food Sci. 1973;38(6):938-40.

3. Desai CS, Desai CD, Desai SK, Mistry PS, Patel JM, Vaidya HB, Preparation of Flavored Candy from Central Core of Banana Pseudo stem. Asian J Dairy and Food Res. 2016;35(4):341-2

4. Saravanan K, Aradhya SM. Potential Nutraceutical Food Beverage with Antioxidant Properties from Banana Plant Bio-Waste (Pseudostem and Rhizome). Food Funct. 2011;2(10):603-10.

5. Laufenberg G, Kunz B, Nystroem M. Transformation of Vegetable Waste into Value Added Products: (A) The Upgrading Concept; (B) Practical Implementations. Bioresour Technol. 2003;87(2):167-98.

6. Prakongpan T, Nitihamyong A, Luangpituksa P. Extraction and Application of Dietary Fiber and Cellulose from Pineapple Cores. J Food Sci. 2002:267(4):130813.
7. Hauner $H$, Bechthold A, Boeing H, Bronstrup A, Buyken A, Leschik BE. Evidence-Based Guideline of the German Nutrition Society: Carbohydrate Intake and Prevention of Nutrition-Related Diseases. Ann Nutr Metab. 2012;60(Suppl 1):1-58.

8. Higgins JA. Resistant Starch: Metabolic Effects and Potential Health Benefits. J AOAC Int. 2004;87(3):761-8.

9. Varga L. Effect of Acacia (Robinia Pseudoacacia L.) Honey on the Characteristic Microflora of Yogurt during Refrigerated Storage. Int J Food Microbiol. 2006;108(2):272-5.

10. Ivbijaro G, Kolkiewicz L, Lionis C. Primary Care Mental Health and Alma-Ata: From Evidence to Action. Ment Health Fam Med. 2008;5(2):67-9.

11. Hossain M, Haque A. Nutritive Value of Jackfruit: Bangladesh J Agric. 1979;4(1):9-12.

12. Teuber T, Perrenten V. Role of Milk and Meat Products as Vehicles for Antibiotic Resistant Bacteria. Acta Vet Sc and Suppl. 2000;93:75-87.

13. Kim HS, Chae HS, Jeong SG, Ham JS, Im SK Ahn CN, et al. Antioxidant Activity of Some Yogurt Starter Cultures. Asian-Australas J Anim Sci. 2005;8(2):255-8.

14. Mondal C, Remme RN, Mamun AA, Sultana S, Ali MH, Mannan MA. Product development from Jack fruit (Artocarpus heterophyllus) and Analysis of Nutritional quality of the processed products volume. J Agric Vet Sci. 2019;4(1):7684.

Article History: Submission Date : 19-01-2020; Revised Date : 27-01-2020; Acceptance Date : 18-02-2020.

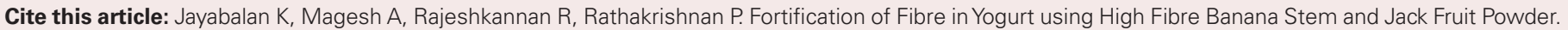
Int. J. Pharm. Investigation. 2020;10(2):127-31. 